\title{
Transoral endoscopic thyroidectomy vestibular approach with intraoperative nerve monitoring
}

\author{
William B. Inabnet III ${ }^{1,2} \cdot$ Hyun Suh ${ }^{1}$ Gustavo Fernandez-Ranvier ${ }^{1}$
}

Received: 3 October 2016/ Accepted: 31 October 2016/Published online: 10 November 2016

(C) Springer Science+Business Media New York 2016

\begin{abstract}
Background Transoral endoscopic thyroidectomy by a vestibular approach (TOETVA) is a novel technique for thyroid gland excision. Compared to the transaxillary endoscopic and bilateral axillo-breast approaches, which require substantial dissection to reach the thyroid gland, TOETVA provides the most direct access to the target organ.

Methods The aim of this video is to provide a step-by-step overview of TOETVA and demonstrate how to set up and utilize intraoperative nerve monitoring.

Results Three incisions are placed in the vestibular region of the oral cavity just below the lower lip for placement of 2 lateral $5-\mathrm{mm}$ trocars and 1 centrally placed $11-\mathrm{mm}$ trocar. Insufflation to $6 \mathrm{~mm} \mathrm{Hg}$ is used to maintain the working
\end{abstract}

spacing. Using a 2-handed technique and triangulation, the thyroid gland is mobilized, taking care to identify and preserve the relevant cervical anatomy.

Conclusion TOETVA is safe and feasible and provides an excellent cosmetic outcome with the most confidentially compared to the other remote access endoscopic approaches.

Keywords Endoscopic · Thyroidectomy · Minimally invasive $\cdot$ Remote access $\cdot$ Transoral

Compliance with ethical standards

Disclosures W. B. Inabnet, H. Suh and G. Fernandez-Ranvier have no conflicts of interest or financial ties to disclose.
Electronic supplementary material The online version of this article (doi:10.1007/s00464-016-5322-y) contains supplementary material, which is available to authorized users.

William B. Inabnet III

william.inabnet@mountsinai.org

1 Icahn School of Medicine at Mount Sinai, New York, NY, USA

2 Department of Surgery, Mount Sinai Beth Israel, First Ave at 16th St, Baird Hall, 16th Floor, Suite 20, New York, NY 10003, USA 